\title{
Comparing Non-Steady State Emissions under Start-Up and Shut-Down Operating Conditions with Steady State Emissions for Several Industrial Sectors: A Literature Review
}

\author{
Juwairia Obaid ${ }^{1}$, Ashraf Ramadan ${ }^{2, *}$, Ali Elkamel ${ }^{1,3}$ and William Anderson ${ }^{1}$ \\ 1 Department of Chemical Engineering, University of Waterloo, Waterloo, ON N2L3G1, Canada; \\ juwairia.obaid@gmail.com (J.O.); aelkamel@uwaterloo.ca (A.E.); wanderson@uwaterloo.ca (W.A.) \\ 2 Environment \& Life Sciences Research Center, Kuwait Institute for Scientific Research, Safat 13109, Kuwait \\ 3 The Petroleum Institute, P.O. Box 2533, Abu Dhabi, UAE \\ * Correspondence: aramadan@kisr.edu.kw; Tel.: +965-2498-9134
}

Academic Editor: George Tsatsaronis

Received: 14 November 2016; Accepted: 1 February 2017; Published: 4 February 2017

\begin{abstract}
This study investigates the emissions of various industrial facilities under start-up, shut-down, and normal operations. The industries that have been investigated include power and/or heat generation, energy-from-waste generation, nuclear power generation, sulphuric acid production, ethylene production, petrochemical production, and waste incineration. The study investigated multiple facilities worldwide for each of these industrial categories. The different potential contaminants characteristic of each industry type have been investigated and the emissions of these contaminants under non-steady state have been compared to the steady state emissions. Where available, trends have been developed to identify the circumstances, i.e., the industrial sector and contaminant, under which the assessment and consideration of emissions from start-up and shut-down events is necessary for each industry. These trends differ by industrial sector and contaminant. For example, the study shows that sulphur dioxide $\left(\mathrm{SO}_{2}\right)$ emissions should be assessed for the start-up operations of sulphuric acid production plants, but may not need to be assessed for the start-up operations of a conventional power generation facility. The trends developed as part of this research paper will help air permit applicants to effectively allocate their resources when assessing emissions related to non-steady state operations. Additionally, it will ensure that emissions are assessed for the worst-case scenario. This is especially important when emissions under start-up and shut-down operations have the potential to exceed enforceable emission limits. Thus, assessing emissions for the worst-case scenario can help in preventing the emissions from adversely impacting public health and the environment.
\end{abstract}

Keywords: start-up; shut-down; emissions; dynamic; non-steady state

\section{Introduction}

In the United States, the regulatory structure and framework pertaining to air permits is dependent on the requirement of a facility to meet emission limits for different contaminants as set out in the applicable regulations [1,2]. The described situation is also applicable outside the borders of the United States, e.g., Ontario in Canada. Thus, facilities must demonstrate compliance with these emission limits by calculating their emissions and comparing them to the limits. The emissions are most commonly calculated using the emission factors listed under AP-42, Compilation of Air Pollutant Emission Factors, published by the United States Environmental Protection Agency (U.S. EPA) [1,3]. The use of these emission factors to estimate emissions is encouraged by regulatory agencies [1,3]. It is 
noted that these emission factors are based on emissions data collected under normal, steady-state process operating conditions [4]. Thus, these emission factors do not consider non-steady state operating conditions where the operating conditions may deviate from the steady-state conditions [4]. Consequently, using these emission factors to calculate the worst case emissions, a scenario which is very likely to occur under non-steady state conditions, is far from ideal. This demonstrates a need for the development and implementation of approaches that more accurately account for emissions attributed to non-steady state conditions. Non-steady state operation can include process start-ups and shut-downs, as well as process upsets [5].

In the United States, different states have adopted different methods of regulating the emissions associated with start-up and shut-down operation [1]. The inconsistencies in their method and regulatory approach are, in part, due to the absence of a clearly defined process of estimating and regulating emissions under such conditions [1]. For example, some states allow the development of site-specific start-up and shut-down emission limits based on a minimum of six months of continuous emissions monitoring system (CEMS) data [1]. Alternatively, other states regulate emission limits for steady-state operation only [1]. Yet other states control excess emissions generated during start-up and shut-down events by limiting the time period allowed for such events [6].

In February 2013, the US EPA proposed a rule that mandated the states to develop plans that required industrial facilities to be in compliance with applicable emission limits during start-up, shut-down, and process malfunctions [6]. This rule was introduced as a result of a US environmental organization, the Sierra Club, filing a petition for the consideration of emissions associated with these non-steady state operating conditions [6]).

Predicting emissions associated with non-steady state operations poses multiple challenges. Due to the variance in process variables and the relative short time span of start-ups and shut-downs, it can be challenging to obtain monitoring data that is accurate and representative [5]. In addition, manufacturer's emissions data relating to start-ups and shut-downs is often unavailable [5]. Moreover, the development and use of a non-steady state dynamic model is often more challenging and expensive than that of a steady state model [7]. Furthermore, the complex relationships between various process functions that are dynamic at the same time during non-steady state operation add to the difficultly in estimating non-steady state emissions [7]).

Although the challenges described above may be cumbersome, time-consuming, and costly to address, developing and implementing methods to predict non-steady state emissions is vital in ensuring that industrial facilities do not exceed air emission limits during these short-term operations. In most cases, emissions associated with start-up and shut-down events are higher than those associated with normal, steady state operating conditions $[6,8]$. Methods of estimating these increased emissions need to be developed so that the facility can be designed such that an increase in emissions during start-up and shut-down does not result in an adverse impact on human health or the environment. Most incidents that are related to the facility's process operations occur when the facility is operating under non-steady state conditions [7]. Moreover, emission limits become more stringent with time. Thus, it is in the best interest of the permit applicants that methods to estimate emissions from start-up and shut-down events be developed, so that they can ensure compliance at the design stage rather than going through higher-cost retrofits. This would also help maintain compliance throughout the life of the facility [1].

This paper focuses on comparing emissions of various industrial facilities under start-up, shut-down, and normal operation from various industries. Where available, trends have been developed to assess the circumstances under which the consideration of emissions from start-up and shut-down events are necessary for each industry. These trends will help air permit applicants to effectively allocate their resources when assessing emissions related to non-steady state operations. 


\section{Methodology}

As part of this investigation, journal articles, research papers, as well as reports prepared by industrial air applicants were researched with a focus on facilities that had assessed and reported their emissions under start-up, normal, and shut-down operating conditions.

The industrial sectors include power and/or heat generation, energy-from-waste generation, nuclear power generation, sulphuric acid production, ethylene production, petrochemical production, and waste incineration. Similar facilities were grouped together and categorized into industrial sectors for better organization and easy identification of emission characteristics by industry. Additionally, facilities within the same industrial sector are very likely to have the same chemical reactions and processes and, hence, have similar emission profiles and principles governing the processes. Any differences between facilities within an industrial sector that led to a different emissions profile were recognized and identified.

For facilities that had quantitatively assessed their emissions under start-up, normal, and shut-down operations, the emissions data was tabulated for each operating scenario. Since the facilities researched were from different countries, the emission variables measured, as well as their units, were different. For example, some papers listed the emission rates under the different operating conditions, others listed concentrations at the stack, whereas yet others listed the maximum off-property ground level concentration.

Since the emissions for any given facility had the same units, comparing the emissions pertaining to each operating condition for the same facility was not affected. However, the challenge came when the emissions data from different facilities within an industrial sector were grouped together to identify trends in emissions based on the operating scenario. The difference in emission variables and units made this comparison between facilities' emissions data difficult.

To deal with this difficulty, the emissions data was normalized to the emissions associated with the normal operating scenario. This means that the emissions pertaining to the normal operating scenario for each contaminant in each facility will be listed as ' 1 ', and the emissions for the start-up and shut-down events will be listed as the factor or multiplier of increase or decrease in emissions based on the normal operating scenario's emissions. This allows for a better comparison of emissions under each operating scenario for each facility, irrespective of the unit, scale, and measured parameter listed in each paper and/or report.

The range of normalized emission values was then tabulated into a single table for each industrial sector by contaminant type for easy analysis and identification of emission trends. These trends were then analysed, summarized, and reported to suggest the circumstances, i.e., the industrial sector and contaminant, under which the assessment of start-up and shut-down emissions should be performed.

\section{Results and Discussion}

\subsection{Power and/or Heat Generation}

Eleven different facilities were investigated under this industrial sector, including combined-cycle power plants, simple cycle gas turbines, reciprocating internal combustion engines, cogeneration power plants, and open-gas turbine power generations [8-17]. Geographically, the facilities were located in Canada, the United States, the United Kingdom (UK) and Australia. All eleven facilities provided emissions data related to the start-up and normal operating conditions. Only five of the eleven facilities also provided emissions data related to the shut-down conditions $[8,9,12,14,15]$. Table 1 summarizes the normalized emissions for each contaminant emitted in each of the facilities that comprise this industrial sector. 
Table 1. Normalized emissions from power and/or heat generation facilities under start-up, normal, and shut-down operating conditions (number of facilities investigated shown in brackets).

\begin{tabular}{ccccc}
\hline \multirow{2}{*}{ Contaminants } & \multicolumn{3}{c}{ Normalized Emissions } & \multirow{2}{*}{ References } \\
\cline { 2 - 4 } & Start-Up & Normal Operation & Shut-Down & \\
\hline $\mathrm{NO}_{x}$ & $0.47-16.67(11)$ & 1 & $1.13-9.26(5)$ & {$[8-17]$} \\
$\mathrm{CO}$ & $2.08-158.85(11)$ & 1 & $3.09-51.85(5)$ & {$[8-17]$} \\
$\mathrm{VOCs}$ & $1.57-156.84(5)$ & 1 & $2.80-94.86(3)$ & {$[8-10,12,14]$} \\
$\mathrm{SO}_{2}$ & $0.31-7.66(9)$ & 1 & $0.31-3.41(4)$ & {$[8-15,17]$} \\
$\mathrm{PM}_{10}, \mathrm{PM}_{2.5}$ & $0.27-1.21(9)$ & 1 & $0.26-1.07(4)$ & {$[8-15,17]$} \\
$\mathrm{CO}_{2}$ & $1.15 \times 10^{-4}-0.25(2)$ & 1 & - & {$[10,13]$} \\
$\mathrm{H}_{2} \mathrm{SO}_{4}$ & $1(2)$ & 1 & $1(1)$ & {$[8,10]$} \\
$\mathrm{NH}_{3}$ & $0.78(1)$ & 1 & - & {$[15]$} \\
formaldehyde & $12(1)$ & 1 & - & {$[17]$} \\
\hline
\end{tabular}

All facilities assessed the emission of $\mathrm{NO}_{x}$ under start-up and normal operating conditions. Five of the eleven facilities also assessed the $\mathrm{NO}_{x}$ emissions under shut-down conditions $[8,9,12,14,15]$. Nine facilities (i.e., approximately $82 \%$ ) out of the eleven demonstrated that the $\mathrm{NO}_{x}$ emissions were approximately 1.7-16.7 times higher for the start-up conditions than for the normal operating conditions [8-10,12-15,17]. As for the $\mathrm{NO}_{x}$ emissions under shut-down, they were approximately 1.1 to 9.3 times higher than those under the normal operating scenario $[8,9,12,14,15]$. The increase in $\mathrm{NO}_{x}$ emissions during start-up is because during start-up, the temperature at the selective catalytic reduction (SCR) system is not high enough to activate the SCR $[12,18]$. Once the temperature of approximately $575{ }^{\circ} \mathrm{F}$ is reached, the SCR system is activated and the system enters a steady-state [12,18]. The activation of the SCR decreases the emissions during the normal operation considerably $[12,18]$. Based on our above findings this decrease is somewhere between $41 \%-94 \%$. During shut-down, the temperature continues to decrease until it drops below the SCR activation temperature and the SCR system is deactivated $[12,18]$. This, again, causes an increase in $\mathrm{NO}_{x}$ emissions during the shut-down of the plant $[12,18]$. Based on our findings, the increase in emissions during shut-down is between $10 \%-830 \%$. The aforementioned figures demonstrate that an air permit applicant should assess the $\mathrm{NO}_{x}$ emissions during start-up and shut-down.

All eleven facilities assessed the emission of $\mathrm{CO}$ under start-up and normal operating conditions Five of the eleven facilities also assessed the $C O$ emissions under shut-down conditions $[8,9,12,14,15]$. All eleven facilities demonstrated that the $\mathrm{CO}$ emissions were about 2.1-158.9 times higher for the start-up conditions than for normal operation while the five facilities demonstrated that the $\mathrm{CO}$ emissions during shut-down were about 3.1-51.9 times higher than the emissions under normal operations. The increase in CO emissions during start-up and shut-down is likely because the air-fuel ratio decreases at low load conditions, causing a decrease in flame temperature and, thus, incomplete combustion conditions [7]. Thus, an air permit applicant should, at minimum, assess CO emissions during start-up and shut-down due to the potential of these emissions to exceed those under normal operation by $110 \%-15,790 \%$ and $210 \%-5090 \%$ during start-up and shut-down conditions, respectively.

Five facilities assessed Volatile Organic Compounds (VOC) emissions under start-up and normal operating conditions $[8-10,12,14]$. Three of the five facilities also assessed these emissions under shut-down conditions $[8,9,14]$. All five facilities demonstrated that the VOC emissions under start-up were approximately 1.6-156.8 times higher than under normal operating conditions while, for the shut-down conditions, the three facilities demonstrated that the VOC emissions were approximately 2.8-94.9 times higher than under normal operating conditions. Similar to the reason for the increase in $\mathrm{CO}$ emissions during start-up and shut-down events, it is likely that the increase in VOC emissions during these operating conditions is attributable to incomplete combustion. Thus, an air permit applicant should, at minimum, assess VOC emissions during start-up and shut-down due to the 
potential of these emissions to increase by $60 \%-15,580 \%$ and $180 \%-9390 \%$ under start-up and shut-down conditions compared to normal operations.

Nine facilities assessed the emissions of $\mathrm{SO}_{2}$ under start-up and normal operating conditions [8-15,17]. Four of the nine facilities also assessed $\mathrm{SO}_{2}$ emissions under shut-down conditions $[8,9,14,15]$. Approximately $89 \%$ of the facilities (eight out of nine facilities) demonstrated that $\mathrm{SO}_{2}$ emissions under start-up conditions were lower than or equal to the $\mathrm{SO}_{2}$ emissions under normal operation [9-15,17]. As for the shut-down conditions, two facilities demonstrated higher $\mathrm{SO}_{2}$ emissions under shut-down conditions, while the other two facilities reported the opposite. The amount of $\mathrm{SO}_{2}$ emitted is a function of the fuel composition and the fuel consumption [19]. Under normal operating conditions, the fuel consumption is higher than during start-up and shut-down and this conforms with the trend observed for $\mathrm{SO}_{2}$ emissions. It should be noted that the $\mathrm{SO}_{2}$ emission for one of the facilities is significantly higher under start-up and shut-down conditions than under normal operation [8]. What might appear to be a contradiction to the common trend observed (i.e., higher $\mathrm{SO}_{2}$ emissions during normal operations due to higher fuel consumption) readily disappears when one realizes this facility has a sulphur recovery system consisting of a thermal oxidizer and a flare. The flare rarely operates under normal operating conditions and operates significantly under start-up and shut-down operation. Similarly, the oxidizer's operation during start-up and shut-down is much higher than during normal operation. The $\mathrm{SO}_{2}$ emissions from this sulphur recovery system results in the $\mathrm{SO}_{2}$ emissions being higher for the start-up and shut-down events than for the normal operation. It should be noted that the $\mathrm{SO}_{2}$ emissions were the same for all operating conditions for the turbine sources, i.e., if the sulphur recovery system had not been a part of the plant, the $\mathrm{SO}_{2}$ emissions would be the same under start-up, normal, and shut-down conditions. The exception in the observed trend should be emphasized because it portrays that the trends being observed and analysed here can be used as rules of thumb, but not as absolute rules. Each facility is unique and, although most facilities may follow a certain expected emission profile, diligence must be exercised on a case-by-case basis for each facility to ensure that the worst case scenario for emissions is captured. Thus, taking into account the applicable exceptions, an air permit applicant does not necessarily need to assess $\mathrm{SO}_{2}$ emissions during start-up and shut-down operations since these emissions are likely to be lower than those under normal operation.

Nine facilities assessed particulate matter (PM) emissions under start-up and normal operating conditions [8-15,17]. Four of the nine facilities also assessed these emissions under shut-down conditions $[8,9,14,15]$. Approximately $89 \%$ of the facilities (eight out of nine facilities) demonstrated that the PM emissions under start-up conditions were equal to or smaller than those under normal operation [9-15,17]. Similarly, 75\% of the facilities (three out of four facilities) demonstrated that the PM emissions under shut-down conditions were equal to or smaller than those under normal operation [9,14,15]. PM emissions, like $\mathrm{SO}_{2}$ emissions, are largely dependent on fuel composition [19]. Since normal operating conditions use higher quantities of fuel compared to start-up and shut-down events, the trend observed is consistent with higher PM emissions expected during periods of high fuel load combustion. However, it should be noted that the PM emission for one of the facilities is significantly higher under start-up and shut-down conditions [8]. This facility is the Great Bend integrated gasification combined cycle (IGCC) power plant, discussed above [8]. Similar to the case of $\mathrm{SO}_{2}$ emissions, considerable PM emissions are produced during the operation of the sulphur recovery system, which results in the rather uncommon observed trend. Thus, and similar to the comment made regarding $\mathrm{SO}_{2}$, an air permit applicant may not need to assess PM emissions during start-up and shut-down. However, for facilities which have an unusual emission profile due to their unique source and operation characteristic configuration, it is important to exercise diligence to estimate the maximum emissions.

Two facilities assessed carbon dioxide $\left(\mathrm{CO}_{2}\right)$ emissions under start-up and normal operating conditions [10,13]. None of the facilities assessed $\mathrm{CO}_{2}$ emissions under shut-down conditions. Although $\mathrm{CO}_{2}$ is a major greenhouse gas, it is not a criteria pollutant. For this reason there has been less 
interest in the past in its monitoring. The two facilities demonstrate that the $\mathrm{CO}_{2}$ emissions associated with start-up conditions are significantly lower than those associated with normal conditions. Primarily, $\mathrm{CO}_{2}$ emission is a function of the amount of fuel that is combusted under complete combustion conditions. Since the normal operating conditions use higher fuel quantities, unlike start-up conditions, and because the operating conditions during normal operation are conducive to complete combustion, $\mathrm{CO}_{2}$ emissions are much higher under normal operation. Thus, an air permit applicant may not need to assess $\mathrm{CO}_{2}$ emissions during start-up. However, one should note that the trend observed for these two facilities might not be representative of the norm of the majority and accordingly, more facilities need to be investigated to validate the observed trend. Additionally, to develop a trend for $\mathrm{CO}_{2}$ emissions during shut-down operation, more facilities need to be investigated.

Two facilities assessed $\mathrm{H}_{2} \mathrm{SO}_{4}$ emissions under start-up and normal operating conditions $[8,10]$, and one of these facilities assessed these emissions under shut-down condition [8]. For both facilities, the $\mathrm{H}_{2} \mathrm{SO}_{4}$ emission remains fixed irrespective of the operating condition. Since the $\mathrm{H}_{2} \mathrm{SO}_{4}$ is a by-product of the $\mathrm{SO}_{2}$ emission, it is likely that the emission of $\mathrm{H}_{2} \mathrm{SO}_{4}$, like the emission of $\mathrm{SO}_{2}$, is also dependent on fuel properties. Thus, it would be expected that the $\mathrm{H}_{2} \mathrm{SO}_{4}$ emissions for start-up and shut-down operating conditions would be lower or equal to that for normal operation. Thus, an air permit applicant may not need to assess $\mathrm{H}_{2} \mathrm{SO}_{4}$ emissions during start-up and shut-down operation. Still, data from only two facilities is not enough to characterize the emissions trend and the emissions of more facilities need to be investigated to establish the correct trend.

One facility assessed the emissions of $\mathrm{NH}_{3}$ under start-up and normal operating conditions and demonstrated that the $\mathrm{NH}_{3}$ emissions under start-up were significantly lower than that for normal operation [15]. This is because $\mathrm{NH}_{3}$ is added to the SCR to reduce $\mathrm{NO}_{x}$ emissions once normal operating conditions had been reached and the SCR had been activated [15]. The addition of $\mathrm{NH}_{3}$ during normal operation results in higher emissions. $\mathrm{The}^{\mathrm{NH}_{3}}$ emissions during start-up may have been from residual $\mathrm{NH}_{3}$ leftover after shut-down. Only one facility was investigated for $\mathrm{NH}_{3}$ emissions during start-up operations, which means our findings could not be conclusive. There is a need to investigate more facilities under start-up, normal, and shut-down conditions in order to establish the $\mathrm{NH}_{3}$ emission trend.

One facility assessed formaldehyde emissions under start-up and normal operating conditions and demonstrated that the formaldehyde emissions during start-up were 12 times higher than under normal operation [17]. For this facility, the formaldehyde emissions for the start-up conditions were calculated empirically based on an adjustment factor from a previous report for a similar plant. As the case for $\mathrm{H}_{2} \mathrm{SO}_{4}$, more work is needed to establish the correct trend for emissions under different conditions.

\subsection{Energy-from-Waste Generation}

Two different facilities were investigated under this industrial sector. The first was an energyfrom-waste thermal treatment facility, located in Durham, Ontario, Canada [20]. The second was the Oglethorpe Power Generation facility, which is a biomass-fuelled electricity generating facility, located in Warren County, Georgia, United States [19]. Table 2 summarizes the normalized (using normal operating conditions) emissions for each contaminant emitted in each of the facilities that comprise this industrial sector. The results show that for all contaminants emitted from the two plants, the emission of each contaminant was higher under start-up conditions than under normal conditions $[19,20]$. The contaminants emitted are as follows: $\mathrm{NH}_{3}, \mathrm{CO}$, hydrogen chloride $(\mathrm{HCl})$, hydrogen fluoride $(\mathrm{HF})$, nitrogen dioxide $\left(\mathrm{NO}_{2}\right), \mathrm{SO}_{2}$, metals, chlorinated polycyclic aromatics, chlorinated monocyclic aromatics, polycyclic aromatic hydrocarbons (PAHs), VOCs, $\mathrm{NO}_{x}$, and (particulate matter 10 micrometers or less in diameter) $\mathrm{PM}_{10}$. 
Table 2. Normalized emissions from energy-from-waste generation facilities under start-up and normal operating conditions (number of facilities investigated shown in brackets).

\begin{tabular}{cccc}
\hline \multirow{2}{*}{ Contaminants } & \multicolumn{2}{c}{ Normalized Emissions } & References \\
\cline { 2 - 3 } & Start-Up & Normal Operation & \\
\hline ammonia & $10(1)$ & 1 & {$[20]$} \\
$\mathrm{CO}$ & $6.37-10(2)$ & 1 & {$[19,20]$} \\
$\mathrm{HCl}$ & $11(1)$ & 1 & {$[20]$} \\
$\mathrm{HF}$ & $13(1)$ & 1 & {$[20]$} \\
$\mathrm{NO}_{2}$ & $1.64(1)$ & 1 & {$[20]$} \\
$\mathrm{SO}_{2}$ & $8.14-14.5(2)$ & 1 & {$[19,20]$} \\
Metals & $8.33(1)$ & 1 & {$[20]$} \\
Chlorinated polycyclic aromatics & $10.00(1)$ & 1 & {$[20]$} \\
Chlorinated monocyclic aromatics & $10.67(1)$ & 1 & {$[20]$} \\
$\mathrm{PAHs}$ & $10.14(1)$ & 1 & {$[20]$} \\
$\mathrm{VOCs}$ & $10.00(1)$ & 1 & {$[19]$} \\
$\mathrm{NO}_{x}$ & $1.67(1)$ & 1 & {$[19]$} \\
$\mathrm{PM}_{10}$ & $2.24(1)$ & & \\
\hline
\end{tabular}

Only two facilities were studied under this industrial sector [19,20]. Additionally, only two of the listed contaminants $\left(\mathrm{CO}\right.$ and $\left.\mathrm{SO}_{2}\right)$ were common contaminants emitted by both facilities. Hence, the emission values for most of the tabulated contaminants are based on one facility only. Additional facilities need to be investigated before developing an emission versus operation conditions trend including shut-down conditions.

\subsection{Nuclear Power Generation}

Limited information was available on the start-up and shut-down emissions of nuclear power generation facilities. One facility was found and investigated under this industrial sector [21]. This facility is a proposed nuclear power plant to be located in Hinkley Point, Somerset, UK. The plant consists of two pressurized reactor units, each having four steam generators. The plant also includes backup diesel generators for power outages. The air quality modelling report for this nuclear power generation facility stated that start-up emissions include formaldehyde, $\mathrm{CO}$, and $\mathrm{NH}_{3}$. Table 3 summarizes the emissions of each of these contaminants during start-up operation.

Table 3. Emissions from a nuclear power generation facility under start-up and normal operating conditions (number of facilities investigated shown in brackets).

\begin{tabular}{cccc}
\hline \multirow{2}{*}{ Contaminants } & \multicolumn{2}{c}{ Normalized Emissions } & \multirow{2}{*}{ References } \\
\cline { 2 - 3 } & Start-Up & Normal Operation & \\
\hline formaldehyde & $0.0243(1)$ & - & \\
$\mathrm{CO}$ & $0.003(1)$ & 1 & {$[21]$} \\
$\mathrm{NH}_{3}$ & $12.48(1)$ & - & \\
\hline
\end{tabular}

According to AMEC Environment \& Infrastructure UK Ltd [21], formaldehyde is generated during the heating phase under start-up conditions, as a result of the thermal decomposition of a pipe insulation material that is used for piping in the reactor building. The thermal decomposition produces steam containing formaldehyde, which is discharged to the atmosphere by the ventilation extraction system. These formaldehyde emissions have the potential to decompose, producing $\mathrm{CO}$ emissions, which are also discharged to the atmosphere through the ventilation system.

Ammonia is also generated during the heating phase under start-up conditions [21]. When the steam generators are shut down for maintenance, they are filled with a lay-up solution consisting of demineralized water, hydrazine, morpholine, ethanolamine, and ammonia to prevent corrosion and 
provide a biological barrier while they are turned off [21]. When the steam generators, and in turn the lay-up solution, are heated during start-up, $\mathrm{NH}_{3}$ is generated and discharged to the atmosphere via exhaust stacks. The report assumes that all the hydrazine in the lay-up solution breaks down to $\mathrm{NH}_{3}$. Since formaldehyde and $\mathrm{NH}_{3}$ emissions are not generated under normal operation, the emissions of these contaminants are higher during start-up operation.

The CO emissions generated during start-up were approximately $0.3 \%$ of the total $\mathrm{CO}$ emissions produced during normal operation when the backup diesel generators are periodically tested [21]. Thus, the CO emissions generated during start-up can be considered negligible.

After investigating this nuclear power plant, it may be concluded that the air permit applicant should, at minimum, assess formaldehyde and $\mathrm{NH}_{3}$ emissions during start-up operation.

Only one facility was studied under this industrial sector [21]. Emissions during start-up operation may differ significantly between different nuclear power plants. For example, another nuclear power plant may not use the same piping insulation and, thus, may not generate the formaldehyde emissions associated with the insulation's thermal decomposition. However, the same power plant may have other sources of start-up emissions. Thus, additional facilities need to be investigated prior to developing and validating a trend for this industrial sector. Emissions from the shut-down of nuclear power plants need to be further explored.

\subsection{Sulphuric Acid Production}

The search for information on the emissions from sulphuric acid production plants did not yield any quantitative case studies of plants. Thus, the trend observed is based on literature sources. A contact sulphuric acid production plant typically consists of fixed bed catalytic reactors, operated adiabatically [22]. Multiple cooling and heating exchange sections control the temperature of the reactors to ensure a maximum reaction rate is maintained [22]. The reaction that governs the production of sulphuric acid is as follows [22,23]:

$$
\mathrm{SO}_{2}+\frac{1}{2} \mathrm{O}_{2} \leftarrow \rightarrow \mathrm{SO}_{3}
$$

$\mathrm{SO}_{2}$ emissions are significantly higher during start-up than during normal operation [22-25]. This is due to several reasons. Firstly, the ratio of sulphur to air is fairly high at start-up, which reduces the reaction rate and consequently emits unreacted excess $\mathrm{SO}_{2}$ [25]. Secondly, the low temperature at start-up also reduces the reaction rate, leading to the emission of unreacted, excess $\mathrm{SO}_{2}$ during start-up [22].

Reference [23] developed a mathematical simulation model of $\mathrm{SO}_{2}$ emissions for a sulphuric acid production plant under steady-state and non-steady state conditions [23]. The model demonstrated increased $\mathrm{SO}_{2}$ emissions during start-up, as high as 3000-4000 ppm while the steady-state design value for $\mathrm{SO}_{2}$ concentration was 500 ppm [23].

Despite the lack of quantitative emissions from facilities, the several literature sources explored conclude that $\mathrm{SO}_{2}$ emissions increase significantly during the start-up of a sulphuric acid production plant. Thus, this can be adopted as a trend for this industrial sector such that an air permit applicant should, at minimum, assess $\mathrm{SO}_{2}$ emissions from the start-up and normal operations of a sulphuric acid production plant. Further investigation is needed prior to developing a trend for shut-down operation.

\subsection{Ethylene Production}

Similar to the comment made on sulphuric acid production, quantitative information pertaining to case studies on ethylene production plants is somehow rare. Thus, literature sources were utilized instead. The start-up of an ethylene plant generates several contaminants in large amounts, particularly due to flaring operations [26]. The flaring can emit large amounts of $\mathrm{CO}_{2}, \mathrm{CO}, \mathrm{NO}_{x}, \mathrm{VOCs}$, highly reactive VOCs, and partially oxygenated hydrocarbons [26]. 
An ethylene plant having an annual production of 1.2 billion pounds can potentially flare approximately 50 million pounds of ethylene during one start-up event [27]. The emissions from the flare would comprise of a minimum of $18.1 \mathrm{t} \mathrm{CO}, 3.4 \mathrm{t} \mathrm{NO}_{x}, 6.8 \mathrm{t}$ of hydrocarbons, and $45.4 \mathrm{t}$ of highly-reactive VOCs [27].

Despite the lack of quantitative emissions from facilities, the literature sources explored conclude that flaring emissions increase significantly during the start-up of an ethylene production. Thus, this can be adopted as a trend for this industrial sector such that an air permit applicant should, at minimum, assess flaring emissions during start-up and normal operations. However, further investigation is required to better characterize common contaminants emitted during flaring operations, and also to develop a trend for shut-down emissions for ethylene production facilities.

\subsection{Petrochemical Production}

Two different facilities were investigated under this industrial sector. The first was a gas processing facility, comprised of two liquefied natural gas (LNG) process trains, located in Town Point, Barrow Island, Australia [28]. The second is a substitute natural gas (SNG) production facility, which relies on gasification of coal and coke and is located in Control City, Kentucky, U.S. [29]. Quantitative emissions data for start-up, normal and shut-down operation is available for the first facility only. Table 4 summarizes the normalized emissions for each contaminant emitted from the LNG processing facility. Emissions have been normalized with respect to the emissions of the normal operating conditions.

Table 4. Normalized emissions from a liquefied natural gas (LNG) processing facility under start-up, normal, and shut-down operating conditions (number of facilities investigated shown in brackets).

\begin{tabular}{ccccc}
\hline \multirow{3}{*}{ Contaminants } & \multicolumn{3}{c}{ Normalized Emissions } & \multirow{2}{*}{ References } \\
\cline { 2 - 4 } & Start-Up & Normal Operation & Shut-Down & \\
\hline $\mathrm{NO}_{x}$ & $0.52(1)$ & 1 & $0.74(1)$ & \\
$\mathrm{NO}_{2}$ & $0.59(1)$ & 1 & $0.78(1)$ & {$[28]$} \\
$\mathrm{PM}_{10}$ & $18.00(1)$ & 1 & $110.00(1)$ & \\
\hline
\end{tabular}

The results show that, for the LNG processing facility, the $\mathrm{NO}_{x}$ and $\mathrm{NO}_{2}$ emissions were lower for start-up and shut-down than for normal operation, while the PM emissions had a reversed trend [28]. However, the results for the SNG production facility demonstrate that there is an increase in the emissions of $\mathrm{CO}, \mathrm{NO}_{x}, \mathrm{SO}_{2}$, VOCs, $\mathrm{PM}$, and lead during non-steady state conditions with the majority of these emissions being due to flaring [29]. The observations of the emissions from the two facilities are quite different, perhaps because the two investigated facilities are not similar enough to be grouped together to develop a trend. Additional facilities need to be investigated before an emission-operating conditions trend could be established.

\subsection{Waste Incineration}

Ten different facilities were investigated under this industrial sector [30-39]. These included continuously- and intermittently-operated incinerators located in Japan, Taiwan, Germany, the United States, Norway and Sweden. The incinerators under consideration combusted various sources of refuse, including municipal solid, organic, laboratory, industrial, liquid, and medical waste. Nine of the ten facilities provided emissions data related to the start-up and normal operating conditions [30-37,39], whereas only five provided data related to shut-down conditions [30,31,35,36,38].

Table 5 summarizes the emissions for each contaminant emitted in each of the facilities normalized with respect to the normal operating emissions. 
Table 5. Normalized emissions from waste incineration facilities under start-up, normal, and shut-down operating conditions (number of facilities investigated shown in brackets).

\begin{tabular}{ccccc}
\hline \multirow{2}{*}{ Contaminants } & \multicolumn{3}{c}{ Normalized Emissions } & \multirow{2}{*}{ References } \\
\cline { 2 - 4 } & Start-Up & Normal Operation & Shut-Down & \\
\hline $\mathrm{CO}$ & $2-69(3)$ & 1 & $30(1)$ & {$[30,36,39]$} \\
$\mathrm{NO} x$ & $0.14-0.45(1)$ & 1 & - & {$[30]$} \\
$\mathrm{PCDD} / \mathrm{Fs}$ & $0.80-2727.27(8)$ & 1 & $0.52-212.12(2)$ & {$[30-35,37,39]$} \\
$\mathrm{HCl}$ & $0.03-0.88(2)$ & 1 & $0.12-0.40(1)$ & {$[31,38]$} \\
$\mathrm{PCDD} / \mathrm{F}$ precursors (PAHs, & $1.81-95$ & 1 & $1.07-21.28$ & {$[35,36,39]$} \\
chlorobenzene, chlorophenols) & & & & \\
\hline
\end{tabular}

Eight facilities assessed the emission of polychlorinated dibenzodioxins and polychlorinated dibenzofurans (PCDD/Fs) under start-up and normal operating conditions [30-35,37,39]. Two of these also assessed the PCDD/F emissions under shut-down conditions [30,35]. Approximately $88 \%$ of the facilities (seven out of eight) demonstrated that the PCDD/F emissions were approximately 2.3-2727 times higher under start-up conditions than under normal conditions [30-34,37,39]. As for the PCDD/F emissions under shut-down conditions, one of the two facilities reported approximately 5.5-212 times higher emissions [30], while the other reported approximately 5\%-50\% lower emissions compared to normal operating conditions [35]. The increase in PCDD/F emissions during start-up and shut-down is likely due to incomplete combustion during these conditions [31-33,38,40]. The reason behind one facility reporting lower PCDD/F emissions under start-up and shut-down conditions, is categorizing the feeding of waste as part of the normal operation. This is unusual as the feeding of waste is typically categorized as part of the start-up process of an incineration plant because the operating parameters do not reach steady state until later [30,31,35]. Thus, an air permit applicant should, at minimum, assess PCDD/F emissions during start-up due to the potential of these emissions to be higher. More facilities need to be investigated before a clear trend for PCDD/F emissions during shut-down operation for this industrial sector can be established.

Three facilities assessed the emissions of precursors of PCDD/F [35,36,39]. These precursors included PAHs, chlorobenzene and chlorophenols [34]. Two facilities assessed the emissions of PAHs under start-up, normal, and shut-down conditions [35,36], whereas one facility assessed the emissions of chlorobenzene and chlorophenol under start-up and normal conditions [39]. All three facilities reported that the emissions of the PCDD/F precursor contaminants were significantly higher under start-up (i.e., approximately 1.8-95 times higher) and shut-down (i.e., approximately 1.1-21.3 times higher) conditions. According to the results, an air permit applicant should, at minimum, assess emissions of the precursor contaminants of PCDD/Fs during start-up due to the potential of these emissions to exceed those under normal operation. Further facilities should be investigated prior to developing a representative trend for the emission of PCDD/F precursors for shut-down operation.

Three facilities assessed the emissions of CO under start-up and normal conditions [30,36,39], and only one of these also assessed the emissions of CO under shut-down conditions [36]. All three facilities demonstrated that the emissions of $\mathrm{CO}$ were 2-69 times higher under start-up conditions. The facility that assessed $\mathrm{CO}$ emissions under shut-down conditions also demonstrated that these emissions were 30 times higher for shut-down conditions. This increase in $\mathrm{CO}$ emissions during start-up and shut-down is likely attributable to incomplete combustion conditions. Thus, an air permit applicant should, at minimum, assess $\mathrm{CO}$ emissions during start-up and shut down conditions due to the potential of these emissions to exceed those under normal operation. Additionally, more facilities need to be investigated to establish a more representative $\mathrm{CO}$ emissions trend for shut down operation.

Two facilities assessed the emissions of $\mathrm{HCl}$ under shut-down and normal conditions [31,38], of which one facility also assessed $\mathrm{HCl}$ emissions for start-up conditions [31]. The results demonstrated that the $\mathrm{HCl}$ emissions under start-up and shut-down conditions were approximately $12 \%-97 \%$ and $60 \%-88 \%$ lower than those under normal operation, respectively [31]. It is likely that the $\mathrm{HCl}$ emissions 
were lower during start-up and shut-down due less waste being combusted during these operating periods, i.e., a reduced amount of chlorine source [31]. Thus, an air permit applicant may not need to assess $\mathrm{HCl}$ emissions during start-up and shut-down. However, more facilities need to be investigated before one can reach a conclusive trend.

One facility assessed the emissions of $\mathrm{NO}_{x}$ under start-up and normal conditions and demonstrated that the $\mathrm{NO}_{x}$ emissions under start-up were approximately $55 \%-85 \%$ lower than those under normal operation [30]. As seen in Section 3.1, $\mathrm{NO}_{x}$ is usually expected to be higher under start-up and shut-down conditions in power generation since the temperature during these operating conditions is too low for the activation of the SCR. Thus, the reason behind this observation cannot be explained. Hence, more facilities need to be investigated in order to establish a more representative trend for $\mathrm{NO}_{x}$ emissions from waste incineration plants.

\section{Conclusions and Recommendations}

The results of this investigation are summarized in Table 6, which summarizes the circumstances under which emissions from start-up and shut-down operations should be assessed for each industry and contaminants that were investigated. Additionally, the table identifies when trends were inconclusive for specific contaminants and industries. When a trend was inconclusive, it is recommended that the emissions from start-up and shut-down operations be assessed to be conservative. This will ensure that emissions have been assessed for all operating conditions and, thus, will ensure that the emissions from the worst case scenario have been assessed. Additionally, assessing and reporting the emissions under these non-steady state scenarios will increase the number of case studies that could serve as a basis for developing emissions trends under these operating conditions.

It is recommended that further case studies be explored for the industries that have been investigated in this research paper to further validate the observed trends and to develop trends where the trend was inconclusive. Additionally, emissions under start-up and shut-down operations should also be assessed for other industries such as polymer production, food production, agriculture, etc. Furthermore, emissions under other non-steady state operating conditions, such as process upsets and malfunctions, should also be investigated to aid in the control of such emissions.

The trends developed as part of this research paper will help air permit applicants to effectively allocate their resources when assessing emissions related to non-steady state operations. Additionally, it will ensure that emissions are assessed for the worst-case scenario. This is especially important when emissions under start-up and shut-down operations have the potential to exceed applicable emission limits. Thus, assessing emissions for the worst-case scenario help prevent the emissions from adversely impacting public health and the environment. 
Table 6. Summary of when emissions from start-up and shut-down operations should be assessed for different industries and contaminants, based on aforementioned trends observed from case studies. Legend: must assess emissions (Y); may not need to assess emissions (N); contaminant not studied (-); and inconclusive, i.e., further investigation necessary to develop a trend (Inc.).

\begin{tabular}{|c|c|c|c|c|c|c|c|}
\hline Contaminants & $\begin{array}{c}\text { Power and/or } \\
\text { Heat Generation }\end{array}$ & $\begin{array}{c}\text { Energy-from-Waste } \\
\text { Generation }\end{array}$ & $\begin{array}{l}\text { Nuclear Power } \\
\text { Generation }\end{array}$ & $\begin{array}{c}\text { Sulphuric Acid } \\
\text { Production }\end{array}$ & $\begin{array}{c}\text { Ethylene } \\
\text { Production }\end{array}$ & $\begin{array}{l}\text { Petrochemical } \\
\text { Production }\end{array}$ & $\begin{array}{c}\text { Waste } \\
\text { Incineration }\end{array}$ \\
\hline $\mathrm{NO}_{x}$ & $\begin{array}{c}\text { start-up: } Y \\
\text { shut-down: } Y\end{array}$ & Inc. & - & - & $\begin{array}{l}\text { start-up: Inc. } \\
\text { shut-down: - }\end{array}$ & Inc. & $\begin{array}{l}\text { start-up: Inc. } \\
\text { shut-down: - }\end{array}$ \\
\hline $\mathrm{CO}$ & $\begin{array}{c}\text { start-up: } \mathrm{Y} \\
\text { shut-down: } \mathrm{Y}\end{array}$ & Inc. & Inc. & - & $\begin{array}{l}\text { start-up: Inc. } \\
\text { shut-down: - }\end{array}$ & Inc. & $\begin{array}{c}\text { start-up: Y } \\
\text { shut-down: Inc. }\end{array}$ \\
\hline Highly reactive VOCs & - & - & - & - & $\begin{array}{l}\text { start-up: Inc. } \\
\text { shut-down: - }\end{array}$ & - & - \\
\hline VOCs & $\begin{array}{c}\text { start-up: } Y \\
\text { shut-down: } Y\end{array}$ & Inc. & - & - & $\begin{array}{l}\text { start-up: Inc. } \\
\text { shut-down: - }\end{array}$ & Inc. & - \\
\hline PAHs & - & Inc. & - & - & - & - & start-up: $\mathrm{Y}$ \\
\hline $\begin{array}{l}\text { PCDD/F precursors (PAHs, } \\
\text { chlorobenzene, chlorophenols) }\end{array}$ & - & - & - & - & - & - & shut-down: Inc \\
\hline $\mathrm{SO}_{2}$ & $\begin{array}{c}\text { start-up: } \mathrm{N} \\
\text { shut-down: } \mathrm{N}\end{array}$ & Inc. & - & $\begin{array}{l}\text { start-up: Y } \\
\text { shut-down: - }\end{array}$ & - & Inc. & - \\
\hline $\mathrm{PM}$ & $\begin{array}{c}\text { start-up: N } \\
\text { shut-down: N }\end{array}$ & Inc. & - & - & - & Inc. & - \\
\hline Chlorinated polycyclic aromatics & - & Inc. & - & - & - & - & - \\
\hline $\mathrm{CO}_{2}$ & $\begin{array}{l}\text { start-up: Inc. } \\
\text { shut-down: - }\end{array}$ & - & - & - & $\begin{array}{l}\text { start-up: Inc. } \\
\text { shut-down: - }\end{array}$ & - & - \\
\hline metals & - & Inc. & - & - & - & - & - \\
\hline $\mathrm{H}_{2} \mathrm{SO}_{4}$ & $\begin{array}{l}\text { start-up: Inc. } \\
\text { shut-down: Inc. }\end{array}$ & - & - & - & - & - & - \\
\hline $\mathrm{NH}_{3}$ & Inc. & Inc. & Inc. & - & - & - & - \\
\hline Formaldehyde & Inc. & - & Inc. & - & - & - & - \\
\hline $\mathrm{PCDD} / \mathrm{Fs}$ & - & - & - & - & - & - & $\begin{array}{c}\text { start-up: Y } \\
\text { shut-down: Inc. }\end{array}$ \\
\hline $\mathrm{HCl}$ & - & Inc. & - & - & - & - & $\begin{array}{l}\text { start-up: Inc. } \\
\text { shut-down: Inc. }\end{array}$ \\
\hline HF & - & Inc. & - & - & - & - & - \\
\hline $\mathrm{NO}_{2}$ & - & Inc. & - & - & - & - & - \\
\hline Partially oxygenated hydrocarbons & - & - & - & - & $\begin{array}{l}\text { start-up: Inc. } \\
\text { shut-down: - }\end{array}$ & - & - \\
\hline
\end{tabular}


Author Contributions: Juwairia Obaid is a graduate student at the University of Waterloo and is the main contributor of this article. The co-authors Ashraf Ramadan, Ali Elkamel and William Anderson contributed equally to the manuscript.

Conflicts of Interest: The authors declare no conflict of interest.

\section{Abbreviations}

$\begin{array}{ll}\text { U.S. EPA } & \text { United States Environmental Protection Agency } \\ \text { CEMS } & \text { Continuous Emissions Monitoring System } \\ \text { SCR } & \text { selective catalytic reduction } \\ \mathrm{NO}_{x} & \text { nitrogen oxides } \\ \mathrm{CO} & \text { carbon monoxide } \\ \text { VOCs } & \text { volatile organic compounds } \\ \mathrm{PAHs}_{\mathrm{SO}_{2}} & \text { polyaromatic hydrocarbons } \\ \mathrm{PM}_{\mathrm{CO}} & \text { sulphur dioxide } \\ \mathrm{H}_{2} \mathrm{SO}_{4} & \text { particulate matter } \\ \mathrm{NH}_{3} & \text { carbon dioxide } \\ \mathrm{PCDD}_{2} \mathrm{Fs} & \text { sulphuric acid } \\ \mathrm{HCl} & \text { ammonia } \\ \mathrm{HF} & \text { polychlorinated dibenzodioxins and polychlorinated dibenzofurans } \\ \mathrm{NO}_{2} & \text { hydrogen chloride } \\ & \text { hydrogen fluoride }\end{array}$

\section{References}

1. Suess, D.; Suess, E.; Gregory, S. Development of Startup and Shutdown Permit Limits Based upon Historical Data from Combustion Sources Monitored by Continuous Emission Monitoring Systems. In Proceedings of the 102nd Annual Conference and Exhibition, Air \& Waste Management Association, Detroit, MI, USA, 16-19 June 2009.

2. Ontario Provincial Government. Ontario Regulation 419/05: Air Pollution-Local Air Quality. Environmental Protection Act. Available online: https://www.ontario.ca/laws/regulation/050419 (accessed on 2 February 2017).

3. Ontario Ministry of the Environment. Procedure for Preparing an Emission Summary and Dispersion Modelling Report; Ontario Ministry of the Environment: Toronto, ON, Canada, 2009.

4. Eastern Research Group Inc. Recommended Procedures for Development of Emissions Factors and Use of the WebFIRE Database; U.S. Environmental Protection Agency: Morrisville, NC, USA, 2013.

5. New Mexico Environment Department. Guidance for Including Emissions during Routine or Predictable Startup, Shutdown, and Scheduled Maintenance in Permit Applications; New Mexico Environment Department: Santa Fe, NM, USA, 2008.

6. United States Environmental Protection Agency (U.S. EPA). State Plans to Address Emissions during Startup, Shutdown, and Malfunction: Proposed Response to Petition for Rulemaking, Findings of Inadequacy, and Call for Plan Revisions; U.S. EPA: Washington, DC, USA, 2013.

7. The Environment Agency. Principles for Determining Start up and Shut down Criteria for Gas Turbines; The Environment Agency: Rotherham, UK, 2011.

8. Ohio Environmental Protection Agency. AEP_Great Bend IGCC Facility: Emissions Inventory; Ohio Environmental Protection Agency: Columbus, OH, USA, 2006.

9. AECOM. Air Permit Application-Volume II-Warren County Combined-Cycle Project. Available online: http:/ / docplayer.net/15902154-Air-permit-application-volume-ii-warren-county-combined-cycleproject.html (accessed on 2 February 2017).

10. Burns \& McDonnell Engineering Company, Inc. Prevention of Significant Deterioration-Air Construction Permit Application; Lacey Randall Station-TradeWind Energy, Inc.: Colby, KS, USA, 2013.

11. SENES Consultants. Air Quality Assessment for the Proposed Portlands Energy Centre; SENES Consultants: Toronto, ON, Canada, 2003. 
12. Macak, J. Evaluation of Gas Turbine Startup and Shutdown Emissions for New Source Permitting; Mostardi Platt Environmental: Chicago, IL, USA, 2005.

13. Itliong, F. Air Quality Impact Study_Green Electron Power Project (East Site); Eastern Power Limited: Toronto, ON, Canada, 2012.

14. Conger, L. Notice of Intent for Sevier Power Company; Meteorological Solutions Inc.: Salt Lake City, UT, USA, 2012.

15. SENES Consultants. Air Quality Assessment for the Napanee Generating Station; SENES Consultants: Toronto, ON, Canada, 2014.

16. Arcadis. Application for Prevention of Significant Deterioration Preconstruction Permit; Oregon Clean Energy Center: Lucas County, OH, USA, 2013.

17. URS Australia Pty Ltd. Air Quality Impact Assessment-AGL Gas-Fired Power Station at Dalton, NSW; AGL Energy Limited: Sydney, Australia, 2009.

18. Bivens, R. Startup and shutdown $\mathrm{NO}_{x}$ emissions from combined-cycle combustion turbine units. In Proceedings of the EPRI CEM User Group Meeting, Chicago, IL, USA, 24 May 2002.

19. Fulle, D. Oglethorpe Power Corporation-Warren County PSD Permit Application Startup Modelling; Oglethorpe Power Generation Corporation: Tucker, GA, USA, 2010.

20. Ollson, C.; Knopper, L.; Aslund, M.; Jayasinghe, R. Site specific risk assessment of an energy-from-waste thermal treatment facility in Durham Region, Ontario, Canada. Part A: Human health risk assessment. Sci. Total Environ. 2004, 466, 345-356. [CrossRef] [PubMed]

21. AMEC Environment \& Infrastructure UK Ltd. Air Quality Modelling Report_EDF Access; AMEC: Somerset, UK, 2011.

22. Mann, R.; Gardner, I.J.; Morris, C. 24 Reactor dynamics and strategies for minimising $\mathrm{SO}_{2}$ emissions during start-up of a contact sulphuric acid plant. Chem. Eng. Sci. 1980, 35, 185-192. [CrossRef]

23. Mann, R. Controlling $\mathrm{SO}_{2}$ emissions during start-up of multi-bed sulphuric acid converters. Trans. Inst. Meas. Control. 1986, 8, 144-150. [CrossRef]

24. Verwijs, J.W.; Kosters, P.H.; Van den Berg, H.; Westerterp, K.R. Reactor operating procedures for startup of continuously-operated chemical plants. AlChE J. 1995, 41, 148-158. [CrossRef]

25. Monsanto Enviro-Chem Systems Inc. Maintaining low SO2 Emissions during Startup and Shutdown; MECS Inc.: Chesterfield, MO, USA, 2010.

26. $\mathrm{Fu}, \mathrm{J} . ; \mathrm{Xu}, \mathrm{Q}$. Simultaneous study on energy consumption and emission generation for an ethylene plant under different start-up strategies. Comput. Chem. Eng. 2013, 56, 68-79. [CrossRef]

27. Xu, Q.; Yang, X.; Liu, C.; Li, K.; Lou, H.H.; Gossage, J.L. Chemical plant flare minimization via plantwide dynamic simulation. Ind. Eng. Chem. Res. 2009, 48, 3505-3512. [CrossRef]

28. Sinclair Knight Merz. The Gorgon Gas Development-Air Quality Assessment; Chevron Australia: Perth, Australia, 2005.

29. Trinity Consultants. Air Permit Application for New SNG Production Facility-Kentucky New Gas; Trinity Consultants: Convington, KY, USA, 2008.

30. Tejima, H.; Nishigaki, M.; Fujita, Y.; Matsumoto, A.; Takeda, N.; Takaoka, M. Characteristics of dioxin emissions at startup and shutdown of MSW incinerators. Chemosphere 2007, 66, 1123-1130. [CrossRef] [PubMed]

31. Neuer-Etscheidt, K.; Nordsieck, H.O.; Liu, Y.; Kettrup, A.; Zimmermann, R. PCDD/F and other micropollutants in MSWI crude gas and ashes during plant start-up and shut-down processes. Environ. Sci. Technol. 2006, 40, 342-349. [CrossRef] [PubMed]

32. Wu, J.; Lin, T.; Wang, L.; Chang-Chien, G.P. Memory effect of polychlorinated dibenzo-p-dioxin and furan emissions in a laboratory waste incinerator. Aerosol Air Qual. Res. 2014, 14, 1168-1178. [CrossRef]

33. Clarke, M. Characterization of cold start and upset conditions in municipal waste combustors. In Proceedings of the Annual Conference and Exhibition, Air \& Waste Management Association, Salt Lake City, UT, USA, 19-21 June 2000.

34. Wang, L.; His, H.; Chang, J.; Yang, X.; Chang-Chien, G.; Lee, W. Influence of start-up on PCDD/F emission of incinerators. Chemosphere 2007, 67, 1346-1353. [CrossRef] [PubMed]

35. Benestad, C.; Hagen, I.; Jebens, A.; Oehme, M.; Ramdahl, T. Emissions of organic micropollutants from discontinuously operated municipal waste incinerators. Waste Manag. Res. 1990, 8, 193-201. [CrossRef] 
36. Yasuda, K.; Takahashi, M. The emission of polycyclic aromatic hydrocarbons from municipal solid waste incinerators during the combustion cycle. Air Waste Manag. Assoc. 1998, 48, 441-447. [CrossRef] [PubMed]

37. Gass, H.C.; Luder, K.; Sunderhauf, W.; Wilken, M. Comparison of dioxins and related compounds in the emission during the start-up procedures at a municipal waste incinerator. Organohalogen Compd. 2004, 66, 935-940.

38. Wang, H.C.; Hwang, J.F.; Chi, K.H.; Chang, M.B. Formation and removal of PCDD/Fs in a municipal waste incinerator during different operating periods. Chemosphere 2007, 67, S117-S184. [CrossRef] [PubMed]

39. Johnke, B.; Stelzner, E. Results of the German dioxin measurement programme at MSW incinerators. Waste Manag. Res. 1992, 10, 345-355. [CrossRef]

40. Lothgren, C.; van Bavel, B. Dioxin emissions after installation of a polishing wet scrubber in a hazardous waste incineration facility. Chemosphere 2005, 61, 405-412. [CrossRef] [PubMed]

(C) 2017 by the authors; licensee MDPI, Basel, Switzerland. This article is an open access article distributed under the terms and conditions of the Creative Commons Attribution (CC BY) license (http:/ / creativecommons.org/licenses/by/4.0/). 